\title{
ARQUitectura deL MOVIMIENTO: ESTACIONES DEL FERROCARRIL EN COLOMBIA, PRESENTE Y ¿FUTURO?
}

\author{
ARCHITECTURE OF THE MOVEMENT: RAILWAY STATIONS IN COLOMBIA: \\ PRESENT AND FUTURE?
}

Pedro Pablo Rojas C.

Recibido: 17 de marzo de 2017

Aceptado: 5 de junio de 2017

\section{Resumen}

El artículo describe modelos arquitectónicos de la estación de tren, vinculando sus características formales y técnicas que, en suma, determinaron el paradigma tipológico de la "arquitectura del movimiento". Se analizan los edificios que hoy subsisten, con relevantes ejemplos de estaciones en Colombia y algunas en América y Europa. La única certeza dentro del panorama de esta arquitectura es su pasado y el estado inminente de ruina en el presente. ¿Se podrá vislumbrar un futuro en el que haya entendimiento sobre cómo actuar frente a estos edificios en pro de la preservación del patrimonio ferroviario?

Palabras clave: sistema ferroviario, tipología, estación, arquitectura, movimiento.

\section{Abstract}

This article describes architectural models of the train station, linking its formal and technical characteristics that, in short, determined the typological paradigm of the "architecture of the movement". We analyse the buildings that today exist, with relevant examples of stations in $\mathrm{Co}_{-}$ lombia and Latin America. The only certainty within the landscape of this architecture is its past and the imminent state of ruin in the present. Can we glimpse a future in which there is understanding on how to act in front of these buildings in favour of the preservation of railway heritage?

Keywords: railway system, typology, station, architecture, movement.

\footnotetext{
* Arquitecto. Especialista en Restauración arquitectónica. Candidato a doctor en Arquitectura con énfasis en Patrimonio. Docente investigador, Facultad de Arquitectura, Fundación Universidad de América, Bogotá, Colombia. Grupo de Investigación: Territorio y Habitabilidad. ORCID: https://orcid.org/0000-0002-4219-6457. pedro.rojas@profesores. uamerica.edu.co
} 


\section{INTRODUCCIÓN}

La llegada del tren en Colombia trajo consigo profundos cambios relacionados con las concepciones de tiempo y de movilidad, y produjo tipologías arquitectónicas reflejadas en la estación de tren y sus componentes como un sistema que, bajo la óptica actual, carecen de un estudio a partir del modelo del edificio de pasajeros y sus consiguientes volúmenes diseñados cada uno con un fin específico.

Fue tal el impacto de la arquitectura de las estaciones, que se tornó en un ícono de referencia para los poblados en los cuales se inscribió; fue un modelo de la exquisitez que permitió la conexión entre el primer mundo con los incipientes poblados y provincias que vieron en esas construcciones una imagen de elegancia, digna de imitar. Muchos inmuebles urbanos reprodujeron el modelo de estos nacientes edificios ferroviarios, que pese a ser netamente públicos, su objetivo no se centró en representar al Estado, sino a la sociedad que los apropió.

No obstante, cada estación era la copia del modelo estilístico de moda en la época, fueron varias las características que contribuyeron en la adaptación y domesticación de un tipo, obedeciendo directamente a respuestas técnicas y funcionales de la operatividad propia del tren. Elementos que, a la luz actual, no se han tenido en cuenta desde el análisis tectónico de las proporciones: ubicación, escala y magnitud, entre otras, reflejados en los edificios ferroviarios que hoy subsisten.

\section{LA RELEVANCIA Y EL SIMBOLISMO DE LA ESTACIÓN}

El término "estación” se refiere, más que a un edificio, a un lugar de parada del tren, e involucra toda construcción que allí se encuentre (Ordóñez, 1995), además, se sintetiza didácticamente como un sistema coherente e integrado (Tartarini, 2001), distante del edificio solitario que el imaginario colectivo uniformemente reconoce.

De hecho, era el edificio público por excelencia y pese a que fue construido por el Estado, no pretendió ser parte de él; por el contrario, trascendió e involucró razones estéticas y simbólicas que generaron apropiaciones en la sociedad, las cuales le dieron carácter, logrando así una connotación sociológica dada más por el lenguaje colectivo de la memoria y de su comunidad, que por el resultado morfológico o tipológico y estilístico reflejado en su construcción (figuras 1 y 2).

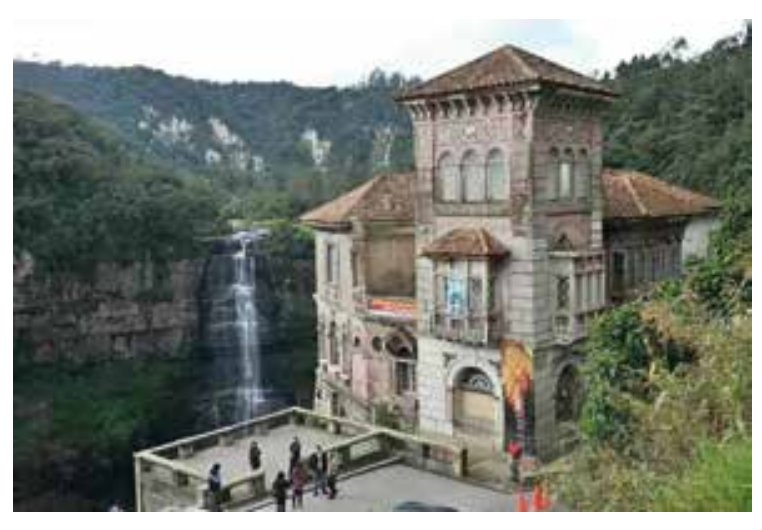

Figura 1. Hotel Estación del Salto, Soacha

Fuente: tomada de http://bogotaenbogota.blogspot.com. co/2011_07_01_archive.html.

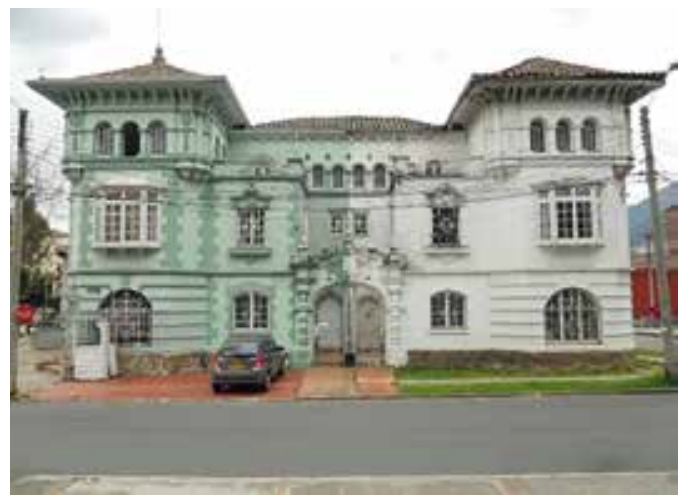

Figura 2. Casona en Teusaquillo, Bogotá Simbiosis e influencia de estilo.

Fuente: fotografía del autor.

La estación fue la concreción de necesidades prácticas y simbólicas (Tartarini, 1995); fue también la síntesis de la cultura ecléctica vigente, la cual vinculó la composición con fuertes conceptos de economía tanto en relación con simetría, regularidad, simpleza y comodidad como en cuanto 
a solidez, salubridad y bienestar. Constituyó sin duda la puerta de entrada a la modernidad, ya que el sistema ferroviario trajo consigo los primeros avances tecnológicos que se originaban en EE. UU. y Europa: el teléfono, el telégrafo, la planta eléctrica, los talleres, los ensamblajes, la metalmecánica avanzada, entre otros; cuyas prácticas funcionales fueron albergadas por edificaciones racionalmente diseñadas para tal fin, las cuales adaptaron y adoptaron el escenario perfecto para los principios y postulados que la modernidad en arquitectura venía profesando.

A su vez, el complejo erigido en la estación como edificio de pasajeros fue el punto de convergencia de actividades sociales ligadas a la construcción colectiva de memoria, al ser un hito social de paso obligado para todos aquellos que entraran o salieran de la ciudad; fue el símbolo no solo de progreso, edilicia o avance, sino la marca que cada poblado tenía, haciéndola única e impenetrablemente apropiada por el morador de cada lugar.

Incluso, el edificio de pasajeros tuvo tal implicación simbólica que forjó una relación analógica del espacio para controlar, en este caso, la movilidad mediante el transporte; creó una "nueva economía del tiempo" (Foucault, 1975), en cuanto a que generó un orden colectivo de los individuos que confluían, quizá, en el único edificio cuya silueta vislumbraba su intrínseca función: confluir para circular.

\section{Metodología}

Se abordó a partir de una investigación básica, en tanto buscó aumentar la teoría relacionándola con nuevos conocimientos, valiéndose del estudio de caso ${ }^{1}$ como estrategia metodológica.

$\mathrm{El}$ análisis tuvo carácter bimodal, iniciando con el enfoque histórico (revisión evolutiva del fenómeno evidenciado en el problema). Luego se empleó el enfoque descriptivo (definición y singularización del objeto de estudio = el patrimonio ferroviario) examinando las características compositivas de la estación de tren y su arquitectura del movimiento desde lo arquitectónico: morfología, tipología, función, estética, constructiva tectónica y contexto. Para tal fin se hicieron visitas en varias estaciones, realizando levantamientos arquitectónicos, haciendo un leve diagnostico funcional actual sin entrar en detalles.

Para el estudio arquitectónico se realizaron visitas a los inmuebles y el territorio que los circunda como fuente directa y primaria, la recolección de datos, inspección ocular, revisión documental, descripción, levantamientos arquitectónicos y fotográficos, tanto del territorio como del paisaje, toda la generalización inductiva encontrada en el caso de estudio.

\section{Fuentes}

Las fuentes primarias de información fueron: inmuebles ferroviarios a lo largo de varias líneas, toda la arquitectura y edilicia encontrada en sitio, el territorio y el paisaje. Así mismo, se utilizaron fuentes de tipo documental: archivos planimétricos del ferrocarril, leyes nacionales o provinciales de libramiento al servicio ferroviario, licencias de obra, contratos, planimetría de traza original, fotografías y postales, archivos históricos, archivos de los Ferrocarriles Nacionales, archivos de la Sociedad Colombiana de Ingenieros e imágenes publicitarias. Además, se contó con los relatos orales tanto de quienes trabajaron en el ferrocarril como de los que vivan cerca a las estaciones o la red ferroviaria.

Así mismo se utilizaron fuentes secundarias tales como: índices de construcción de tendidos, revistas y artículos sobre el tren y patrimonio ferroviario, catálogos, diccionarios y enciclopedias técnicas, memorias sobre seminarios de patrimonio industrial, legislación, entre otras.

\footnotetext{
${ }^{1}$ Se escogió como estudio de caso el patrimonio ferroviario colombiano para poder comprender las dinámicas actuales dentro de un singular contexto geográfico y urbano, que, dadas sus características, se repite en otros contextos internacionales.
} 


\section{Resultados}

Una vez analizados los inmuebles, la cartografía, las fotos, los planos y el contexto de la arquitectura del movimiento evidenciada en las estaciones del caso colombiano, y de acuerdo con un análisis general, se estableció una diferenciación ${ }^{2}$ basada en características formales, urbanas, monumentales, estéticas, de escala y proporción; por lo cual se definieron cuatro tipos de estaciones (ver tabla 1) comúnmente evidenciadas en otros países: Tipo 1. Estación terminal urbana: con características arquitectónicas de monumentalidad e inmersa dentro de una ciudad de relevancia demográfica. Tipo 2. Estación intermedia: con características arquitectónicas y composición formal sobresaliente, inmersa dentro de un centro urbano. Tipo 3. Estación media: con algunas características arquitectónicas, inmersa en algún poblado y poseedora de elementos de valor estético (Daly, 1846). Tipo 4. Estación paradero: una composición de un solo volumen, de escala pequeña, alejada del poblado urbano e inmersa en un marco rural.

Tabla 1. Análisis de estaciones, extracto de las tipo 1-terminal urbana

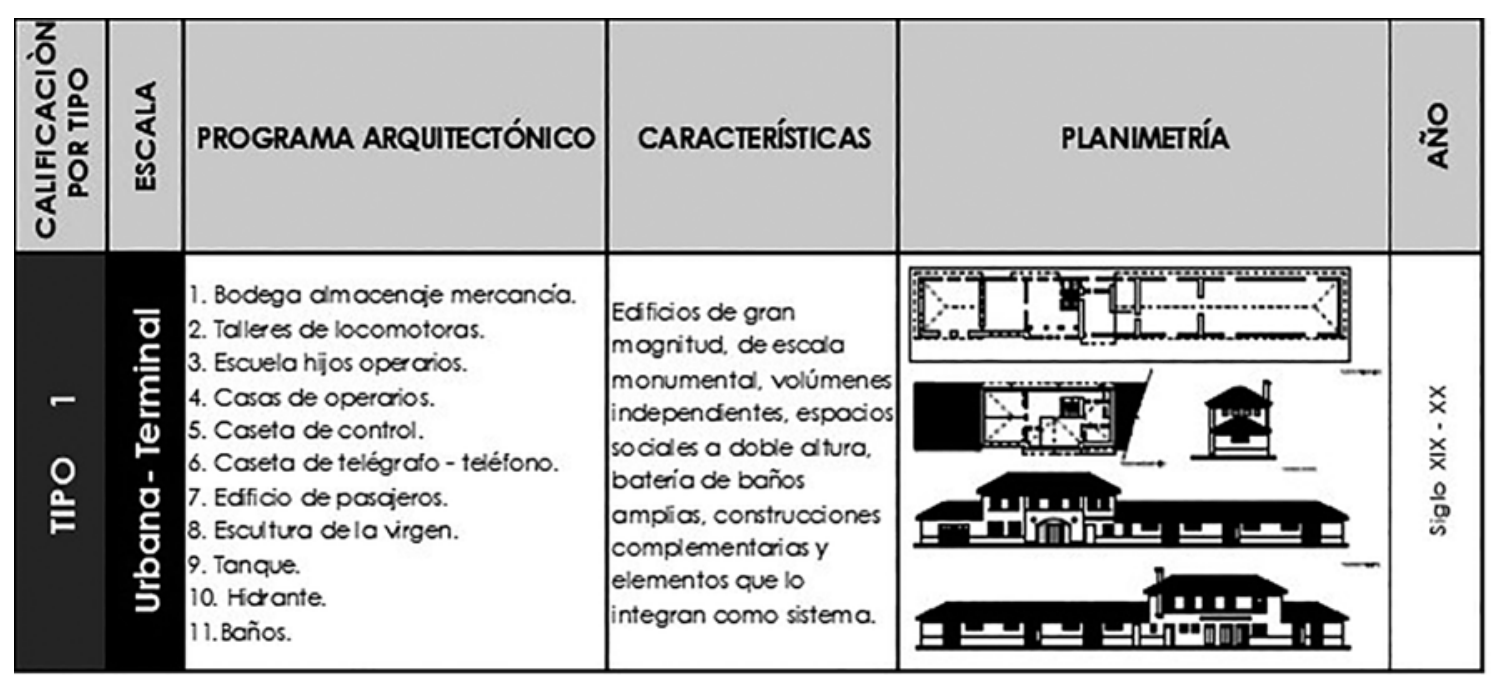

\section{El modelo de la estación y sus implicaciones formales}

El estudio del modelo tipológico de la estación se inició una década después de construida la primera en Crown Street, en Liverpool (Inglaterra, 1830), por Camille Polonceau y Víctor Bois en 1840, los cuales diferenciaron las estaciones construidas hasta entonces en cuatro tipos: las tipo "cabecera"; con los edificios laterales a los rieles; las de tipo "L" y con los edificios al costado de la línea. Posterior a este estudio, Louis Le Chatelier (París, 1845), publicó Chemins de fer d'Allemagne, una investigación de los tipos de estaciones de tren, la cual introdujo novedosamente ejemplos relevantes de edificios construidos analizados comparativamente. Estudios como este y otros fueron sistematizando progresivamente los tipos edificatorios ferroviarios del momento.

Europa poseía singulares ejemplos edificados los cuales seguían postulados de los tratados de arquitectura e ingeniería en sus edificios ferroviarios, puesto que contaron con arquitectos que moldearon las formas como: Henry Richardson y Daniel Burnham; o ingenieros que construyeron dichas ideas como: Thomas Telford o Kingdom Brunel, que en suma produjeron un repertorio

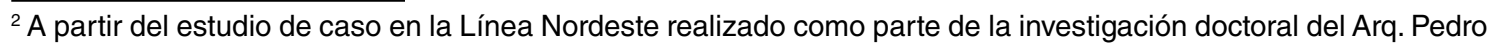
P. Rojas.
} 
"monumental" digno de análisis y estudios posteriores. Otros tratadistas que importa citar son L. Cloquet, quien, en 1900, sostenía que "la estación es la nueva puerta de la ciudad, por lo cual debe presentar un aspecto monumental” (Cloquet, 1900, p. 65), y Leonce Reynaud, el cual argumentaba que "una arquitectura nueva requiere de formas nuevas, y como tal debe poseer una independencia total con las formas del pasado" (Reynaud, 1867, p. 189), haciendo alusión al marcado movimiento "neo" que se dio, y al ya implantado eclecticismo que impedía acentuar las ideas de la modernidad en la arquitectura de aquel entonces.

Más extrema fue la crítica hecha a la estación de tren por parte de J. Ruskin en su libro Las siete lámparas de la arquitectura (en el capítulo titulado "La lámpara de la belleza", 1849), oponiéndose rotundamente a la decoración, en concordancia anticipada con lo decretado posteriormente por Adolf Loos ${ }^{3}$ —en el artículo "Ornamento y delito" de 1908-, por ser lugares transitorios, en los que el afán impide apreciar la belleza del decoro calificando como "tontería flagrante la ornamentación en todo lo relacionado al tren" (Loos, 1908, p. 87).

Pero si estas implicaciones se dieron en los países del primer mundo, donde prácticamente se ideó la mayoría de los modelos arquitectónicos y se dio un auge estético-técnico y funcional, en una época netamente industrial, qué se podría esperar de países suramericanos jóvenes, carentes de un estilo propio, que estaban mirando al primer mundo como modelo e improvisando en cada una de sus construcciones, que no solo fueron las de tipo ferroviario. En el Cono Sur, no se experimentaron patrones de producción industrial tan connotados como en Europa, pues muchas veces hubo que importar, incluso los materiales con los cuales se construirían los edificios ferroviarios. No obstante, como dijo Le Chatelier: "La creación artística es más lenta que la evolución industrial" (1845, p. 197), lo cual no demerita los incansables intentos por alcanzar el ideal del modelo ferroviario internacional, algo bastante complejo para algunos países con procesos de modernización disparejos.

La repetición es un aspecto coincidente de la arquitectura de la estación de tren, y de acuerdo con las compañías constructoras, que insistían en un patrón que implantó modelos a lo largo y ancho de los tendidos férreos en Colombia y el mundo, aunque precisando marcados acentos en algunas líneas sobresalientes. Por ende, la cronología constructiva de estaciones se reflejó en la concreción de modelos tipológicos reconocidos notoriamente ${ }^{4}$, inmersos dentro del eclecticismo preponderante de la época que, sin embargo, evidenciaron rasgos distintivos los cuales se clasifican en cuatro estilos: neocolonial, ecléctico tardovictoriano, revival neocaliforniano y ecléctico simple (Rojas, 2016). No obstante, se pueden evidenciar algunos otros que no se incluyen en este artículo.

Toda empresa contratada para realizar líneas férreas consignaba en los parágrafos de sus contratos las especificaciones tectónicas y técnicas para cada estación. En varios de los documentos consultados, como por ejemplo, en el relativo al Ferrocarril de la Sabana (Empresa del ferrocarril de Cundinamarca, 1887), existe una meticulosa descripción de cómo se debía construir el edificio de pasajeros junto con el sistema complementario que apoyaba el funcionamiento del tren, lo cual dictaminaba, en parte, un estilo predeterminado que se reflejaría en el inmueble terminado.

\section{El funcionamiento y los componentes de la estación como un sistema}

El complejo funcionamiento de la estación estaba dado, en parte, por características técnicas propias de los trenes, incluso anteponiéndose muchas veces a las necesidades de movilización tanto de carga como de pasajeros; en varios casos, los edificios fueron ubicados en zonas completamente alejadas de los núcleos urbanos, debido a la poca pendiente que el tren podía solventar, implican-

\footnotetext{
${ }^{3}$ Adolf Loos criticaba toda manifestación de ornamento en edificios públicos, sobretodo en estaciones de tren por tratarse de espacios para circular más allá de permanecer.

${ }^{4}$ Tal es el caso de la Línea Nordeste, construida por la compañía belga Chamins de Fer.

${ }^{5}$ Estos estilos han sido discriminados por el autor en el trabajo de tesis doctoral "Patrimonio ferroviario en Colombia".
} 
do que topográficamente se dispusieran las paradas en las partes bajas, para no alterar el trazado longitudinal de la línea (figura 3).

Así mismo, como la locomotora requería para el funcionamiento de la caldera que se abasteciera de agua cada cierta cantidad de kilómetros, en algunas estaciones se construían tanques de connotada proporción. Lo mismo ocurrió con los poblados que eran puntos industriales de relevancia ${ }^{6}$, donde se generaba una estación con mayor cantidad de componentes, incluso con un programa que se iba ajustando al sitio.

Para ser un sistema, el conglomerado debía tener: composición, estructura, entorno y conjunto ferroviario relativo al tren, cuyo entendimiento se basa en analizar un movimiento "constructor que se convirtió en uno de los repertorios arquitectónicos más integrados y sistematizados de la historia" (Ferrari, 2011, p. 48).

Los componentes de la estación como sistema se pueden agrupar en zonas con base en un programa funcional: (I) zona pública: edificio de pasajeros, baterías de baños, escultura de la virgen del Carmen (patrona de los conductores), escuelas, tanques e hidrantes, y agujas. (II) Zona semipública: bodegas y talleres. (III) Zona privada: viviendas para operarios, caseta de operario, caseta de telégrafo o teléfono.

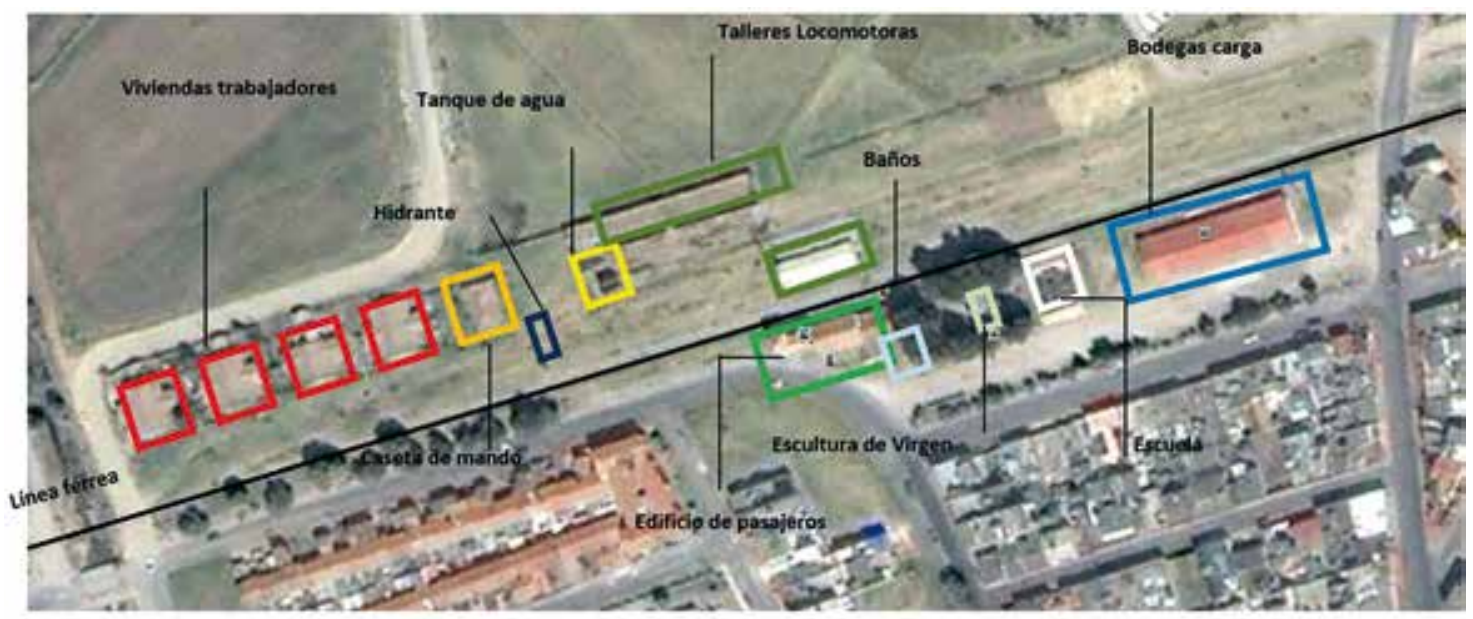

Figura 3. Componentes del sistema ferroviario estación de Sogamoso-Boyacá.

\section{Declive y fin del sistema ferroviario: el Banco Mundial y la trocha angosta}

Colombia progresó de la mano de los ferrocarriles desde el siglo XIX, por la construcción de la infraestructura necesaria para su funcionamiento, lo cual fue interrumpido, junto a variadas obras ${ }^{7}$, —en parte - por recomendación de la Misión Currie de 1949, comisión enviada por el Banco Internacional de Reconstrucción y Fomento (BIRF), ente financiero mundial fundado casi simultáneamente con el Fondo Monetario Internacional (FMI), como consecuencia de la II Guerra Mundial, con el "supuesto" ánimo de brindarle al país un novedoso y moderno sistema de desarrollo y adelanto económico.

\footnotetext{
${ }^{6}$ Se puede observar en estaciones de La Caro, Duitama y Sogamoso, inmersas en las ciudades intermedias con alta vocación industrial en la explotación del acero y derivados del mismo.

${ }^{7}$ Los ferrocarriles construyeron escuelas para hijos de trabajadores quienes generalmente vivían en torno a la estación, que a su vez suministraba el fluido eléctrico de manera gratuita, además de agua, teléfono y telégrafo; y contribuyeron a la construcción de equipamientos como parques, hoteles, clínicas, zonas verdes, entre otros.
} 
Las recomendaciones de la Misión Currie en torno al futuro de los ferrocarriles colombianos fueron tachadas, incluso, como "diabólicas" y comunicadas al gobierno en 1950 por el Banco Mundial. El informe denominado Bases de un programa de fomento para Colombia, comúnmente conocido como el Informe Currie, fue fruto del estudio realizado en tan solo cuatro meses ${ }^{8}$ (Cárdenas, 2001), lo cual suscitó el decaimiento económico y productivo del tren al condenarlo a su inoperancia como medio de transporte. En tal virtud, es claro que el Banco Mundial no favoreció a los ferrocarriles (Cárdenas, 2001). Por el contrario, impuso sus créditos y préstamos financieros, y ofreció artículos y maquinaria bastante usados en Norteamérica. Tal es el caso de la cantidad de automotores y maquinaria que debía vender los Estados Unidos, posterior a la Primera Guerra Mundial, específicamente camiones y automóviles para un país cuya topografía es abrupta y agreste con acentuadas complicaciones en la comunicación terrestre.

No obstante, recomendaron nefastamente destruir al tren para favorecer la carretera, para implantar al camión como medio de carga bajo la premisa de la flexibilidad, opacando la alta operatividad del tren bajo críticas de anticuado, ineficiente y antieconómico.

Otra aseveración incoherente de dicho informe fue decir que las reparaciones y repuestos eran costosos para las locomotoras a vapor, dada la falta de mano de obra experta e idónea, esto iba en contravía de la demostrada sapiencia técnica del personal ferroviario colombiano altamente calificado. La idea era "a como diera lugar" venderle al país la enorme cantidad de vehículos, camiones y equipos de carretera producidos directamente por los EE. UU. (Currie, 1950). Las medidas amparadas y dictaminadas por dicho informe estaban a favor de las carreteras y los camiones, lo cual constituyó un modelo económico dictatorial que se replicó en varios países de Suramérica.

Desafortunadamente, las vías férreas de países como Costa Rica, El Salvador, Guatemala, Venezuela, Ecuador, Perú y Colombia, en su mayoría, se encuentran abandonadas, y en muchos casos, desmontadas y sin rieles, lo cual las convierte en un grave perjuicio para sus perspectivas económicas. Esta es una situación general de los países suramericanos, en los cuales se han arrasado y vendido los bienes públicos a favor del sector privado, todo bajo el amparo del Fondo Monetario Internacional que ordena subir o bajar tarifas, aumentar impuestos, desmontar subsidios, entre otras cosas, para que estos países tengan dinero efectivo con el cual pagar su deuda externa, bajo la mirada y supervisión frecuente del FMI. Factor decisivo en el declive "anunciado" del sistema ferroviario, relacionado con las precarias condiciones económicas en medio de las cuales empezaron a funcionar los ferrocarriles, en la mayoría de los casos. Es importante hacer notar cómo la economía nacional en el siglo XIX era del todo precapitalista; no existía un banco central ni una moneda única nacional y eran usuales el trueque y la permuta, modalidades que no han desaparecido del todo (Cárdenas, 2001).

Esta escasez de recursos, así como el incierto curso de los gobiernos y de sus proyectos, hizo que desde un comienzo se optara por el uso de soluciones "económicas" que permitieran llevar a efecto las obras, aún en medio de las limitaciones. No sobra señalar cómo hoy en Colombia (2017) algunas obras que han sido sugeridas por organismos multilaterales y en realidad han resultado no solo más costosas, sino que condujeron a un esquema de improvisaciones todavía no superado. ${ }^{9}$

En el sentido de aplicar este tipo de soluciones, se manifestó el ingeniero y contratista cubanoamericano Francisco Javier Cisneros quien desde su arribo fue visto como un gran técnico en el

\footnotetext{
${ }^{8}$ Hecho entre el 11 de julio y el 15 de noviembre de 1949, publicado en 1950. Participaron diecinueve expertos extranjeros y dieciséis expertos colombianos quienes analizaron todo el contexto productivo colombiano, generando alta deuda externa al país y condenándolo a créditos costosos para implementar la modernización dependiente de los citados bancos.

${ }^{9}$ Hechos recientes como las dobles calzadas en avenidas nacionales, la Avenida Calle 26, el Aeropuerto El Dorado en Bogotá, la refinería de Cartagena, entre otros, lo confirman.
} 
trazado de ferrocarriles, pero como se descubrió, era un hábil contratista y comisionista que buscaba reducir costos para así acrecentar sus utilidades (Mayor, 2010). Para ello, bajo el argumento de una mayor rapidez en la ejecución de las obras, este ingeniero -imitado luego por otros contratistas-, impuso la vía angosta como "solución" a las dificultades derivadas de la topografía y la escasez de recursos ${ }^{10}$. En realidad, de este modo, el único beneficiado fue el contratista, ya que la cantidad y los costos de materiales como las traviesas, el balasto y los rieles, disminuyeron.

Bajo las condiciones impuestas por contratistas como Cisneros y con una visión de muy corto plazo, los gobernantes locales y nacionales creyeron que era más conveniente llevar a cabo el mayor número de kilómetros de vía férrea, sin tener en cuenta las limitaciones que deberían enfrentarse en el futuro ${ }^{11}$ (Mayor, 2010). Esto pronto se evidenció, cuando iniciándose el siglo XX, en 1908, se puso en funcionamiento el ferrocarril de Girardot. En el tendido entre esta ciudad y Facatativá, se debieron de superar grandes dificultades como las inevitables pendientes del 3 al $4 \%$, y los radios de giro cortos, menores a los usuales; en una de estas pendientes se recurrió incluso a la figura de un asombroso zigzag ${ }^{12}$.

En esta vía pronto se pudo observar cómo casi ninguna de las locomotoras existentes podía operar halando convoyes de alguna magnitud, con pendientes como las aquí existentes y radios de giro en extremo estrechos (Arias, 2006). El costo y el tiempo transcurrido desde el comienzo de las obras, además de la gran actividad económica de este corredor férreo, precisaba de rápidas soluciones, por tal motivo, se recurrió a la adquisición de algunos modelos por entonces poco frecuentes y costosos como las locomotoras de tipo Compound (Arias, 2006), articuladas con doble sistema motriz, cuyo fabricante era la firma británica Kitson-Meyer, y otras con tres cilindros, el tercero interno, del fabricante alemán Berliner Schwartzkopf.

\section{Estado actual del patrimonio ferroviario colombiano}

Hoy el sistema ferroviario en Colombia se encuentra fragmentado, con edificios carentes de función y sin un conocimiento ni una apropiación social. Esto puede verificarse en el hecho de haber sido declarado bien patrimonial, pero con un reconocimiento dado solo a los edificios de pasajeros, sin tener en cuenta que ellos forman parte de un sistema mayor, y concedido tras el declive del sistema ferroviario colombiano. Este problema no es un dilema solo de Colombia: varios países europeos y latinoamericanos han experimentado el abandono de sus infraestructuras ferroviarias durante el final del siglo XX. No obstante, muchos de ellos han reutilizado sus vías férreas con otras funciones como ciclo vías, vías verdes o corredores, entre otras cosas, pero aún se plantea qué hacer con los edificios ferroviarios.

Si bien la Carta Internacional de Nizhny Tagil (TICCIH, 2003) sobre Patrimonio Industrial establece unas premisas para la conservación en general, no existen al menos en el ámbito nacional un conocimiento exhaustivo del patrimonio en cuestión, y menos aún pautas de cómo se debiera proceder para la reutilización de los edificios. Lo anterior se evidencia en el desconocimiento sobre el

\footnotetext{
${ }^{10}$ Desde el momento de la consumación de la independencia en el año de 1821, se hizo patente la inexistencia de recursos por parte de un estado que, siguiendo los esquemas económicos coloniales, dependía de la extracción minera y de las rentas estancadas. Esto se vio agravado con la irrupción del libre cambio, que determinó la destrucción de la frágil industria artesanal que pese a todo subsistió hasta el final del periodo colonial (Bértola y Gerchunoff, 2011).

${ }^{11}$ Nota contextual tomada de Francisco Javier Cisneros (1836-1898) por Alberto Mayor Mora, donde se refieren aspectos hasta hace poco desconocidos de este personaje, reconocido entonces como poco menos que un empresario heroico, pero que además de hábil contratista, buscaba por este medio adquirir concesiones y beneficios sobre territorios calificados desdeñosamente por la clase dirigente como "baldíos". La vía angosta de una yarda equivale a tres pies (0.9144 metros).

${ }^{12}$ El del municipio de la Esperanza, en Cundinamarca.
} 
patrimonio y la falta de aprovechamiento por cuanto edificios y vías ferroviarias son reutilizables para desarrollar proyectos bajo pautas y criterios de análisis que permitan su reutilización y sostenibilidad.

\section{Reconocimiento como sistema patrimonial}

Pese a que los edificios de pasajeros, conocidos como "estaciones de tren", tienen una declaratoria patrimonial solo puntual ${ }^{13}$, no se ha hecho un verdadero proceso de valoración por estar dentro de zonas aisladas territorialmente y ser considerados hitos singulares en lugares recónditos. Razón por la cual se deben analizar las estaciones desde la óptica del sistema patrimonial complejo, el cual plantea que la importancia no está en un solo elemento (Osorio y Acevedo, 2008), sino que surge de la dinámica de los distintos valores y atributos presentes en el sistema ${ }^{14}$ relacionados entre sí. Tales relaciones a su vez produjeron cambios y transformaciones en el territorio y las urbes, ya que el tren propició una serie de actividades económicas que impactaron el espacio y produjeron nuevas poblaciones (Ferrari, 2011a).

Bajo esta óptica es fundamental el análisis de la relación con el territorio: esta juega un papel preponderante y es crucial para la comprensión de los modelos y las formas que produjeron y alteraron los trazados ferroviarios. En la conformación del paisaje, la implantación de los rieles tuvo una capital importancia, ya que el territorio fue transformado y se convirtió en el escenario propicio (Montañez, Rodríguez, Torres y Flórez, 1997) para la interacción entre arquitectura, rieles, sociedad, técnica y uso.

Las concepciones teóricas sobre cómo actuar con el patrimonio siempre han estado enmarcadas dentro del ámbito de la preservación y conservación arquitectónica, sumado a la idea de "museificar" ${ }^{15}$ toda construcción antigua en cuanto a función se refiere. A la luz de evidencias actuales, se vienen presentado actuaciones erradas e incoherentes en muchos inmuebles, debido a la insistencia de proseguir con los usos y funciones originales pese a su no subsistencia.

La conservación del patrimonio propende por la salvaguarda y el mantenimiento de los vestigios históricos, protegiendo los valores del bien que son atributos otorgados a los objetos mediante los cuales se ha definido el patrimonio cultural (Martínez, 2005). Esta definición establece en general el campo de acción de la investigación, siendo preponderante en la evaluación del sistema, en el cual el territorio se transforma en telón cultural como espacio geográfico de contexto, donde interactúa el sujeto que valora el objeto ${ }^{16}$ y es parte inherente al hablar de los tendidos ferroviarios.

Un complejo ferroviario o, en sentido estricto, una estación, se compone de una serie de usos complementarios al tren plasmados en elementos edilicios como: edificio de pasajeros, baños, depósitos, bodegas, tanques, viviendas, talleres, entre otras cosas. A su vez, todos estos elementos normalmente subsisten con un complejo sistema territorial integrado por puentes y túneles, entre otros, razón por la cual no es responsable afirmar que únicamente el edificio de pasajeros compone el patrimonio ferroviario ${ }^{17}$. Por tanto, el sistema ferroviario se define como la infraestructura que

\footnotetext{
${ }^{13}$ Decreto $N^{\circ} 746$ de 1996, por el cual se declara como Monumento Nacional al conjunto de las estaciones de ferrocarril existentes en el país. Otorgándola solo a los edificios de pasajeros.

${ }^{14}$ Respecto a los sistemas patrimoniales complejos.

${ }^{15}$ Término utilizado por Cotalero Grego (1989) respecto a que el monumento no debe convertirse en una pieza de museo, pues la arquitectura no está destinada solamente a la contemplación, sino también a ser utilizada.

${ }^{16} \mathrm{Al}$ hablar de valoración se deben tener en cuenta que todo objeto es digno de valor, definida por un sujeto e inmersa dentro de un contexto.

${ }^{17}$ La teoría de sistemas fue planteada por Bertalanffy en 1950. Su objetivo es realizar estudios interdisciplinares que establezcan los principios claves para aplicar a cualquier tipo de sistema, en cualquier clase de investigación. De igual forma el término ferroviario, como asociación relativa al ferrocarril, alusivo a la vía férrea, los tendidos y edificios cercanos a la red.
} 
incluye todas las instalaciones y construcciones necesarias para el funcionamiento del ferrocarri ${ }^{18}$. Es este el caso de los edificios que componen el patrimonio ferroviario el cual se ha descontextualizado por completo, debido a la ausencia de la función para la cual se crearon y la incertidumbre sobre qué se puede albergar en estos antiguos inmuebles; más aún, el enorme problema es: ¿qué funciones nuevas se les puede dar a estas construcciones antiguas, que estén en concordancia con las dinámicas actuales?

\section{Conservación y valoración del patrimonio ferroviario en torno al futuro}

En Colombia, hasta el día de hoy, tanto la idea de valorar como la de actuar en el patrimonio ferroviario se ha caracterizado por un desconocimiento en tres niveles: i) del objeto patrimonial en sí mismo: ¿en qué consiste el patrimonio ferroviario?; ii) de las pautas generales que orienten una planificación: ¿qué hacer con el patrimonio abandonado?; y iii) de las premisas que deben guiar la intervención: ¿cómo intervenir? y ¿bajo cuáles principios?

A la luz de estas premisas se vislumbra que dicha idea de actuación patrimonial en general ha sido variada e interpretada desde distintas vertientes, tanto proteccionistas como conservacionistas, que utilizan una serie de modelos basados —en parte - en las acciones que dictaminan las cartas internacionales de patrimonio, pese al enorme desconocimiento y vacío teórico que actualmente existe sobre la reutilización del mismo. Actualmente subsisten a lo largo de los tendidos ferroviarios los edificios de las estaciones, abandonados, deshabitados, sin ningún tipo de uso (ni ferroviario, ni de otro tipo por parte de los habitantes cercanos a los mismos), e inclusive con la posibilidad —en algunos casos- de colapsar por su avanzado estado de deterioro; dichos edificios esperan intervenciones tendientes a favorecer su puesta en valor, que sean garantes de su propia sostenibilidad.

Por lo anterior y en aras de prever un futuro y garantizar ciertas actuaciones sobre este legado construido, se debe propender por prácticas proyectuales que desde la academia inciten a desarrollar abordajes teóricos, conceptos de uso e intervenciones coherentes con la edilicia construida y la necesidad de función que garantice la sustentabilidad de lo que allí se pretenda realizar. Se podrían utilizar abordajes teóricos y aplicar metodologías de intervención en patrimonio a partir de concepciones dinamizantes ajenas a la restauración de los hechos construidos: llámese reciclaje arquitectónico, refuncionalización, adecuación o adaptación funcional. Ante todo, cualquier proyecto patrimonial se debe abordar bajo una óptica innovadora y de respeto, "al reconstruir no un espacio, sino un sentimiento espacial" (Arango, 1989, p.106) con elementos virtuales.

Esto se ha evidenciado en las transformaciones generadas por los medios de transporte, que han suscitado nuevos tipos de lenguajes y patrones reflejados directamente en los edificios destinados no solo al transporte, sino a usos complementarios en general. Por ende, los cambios producidos requieren de una nueva arquitectura y la adaptación de la ya construida.

Se deben incorporar conceptos como la reutilización y el reciclaje arquitectónico, específicamente en lo referente a las estaciones de ferrocarril, entendiendo estos como nuevas asignaciones de funciones dentro del edificio antiguo, con un volumen que supla y complemente el programa arquitectónico y garantice la sostenibilidad del bien. Esto deberá enmarcarse dentro de una arquitectura de vanguardia y de respeto por el pasado con miras hacia el futuro, utilizando tecnologías que jueguen con la estética de lo existente y resalten sus valores mediante el contraste y no la repetición y la mímesis.

El futuro del patrimonio ferroviario dependerá, no solo, de las acciones que desde la academia se realicen (un pilar fundamental para su preservación), sino también de políticas estatales, gubernamentales, distritales y locales que determinen si se utilizará este medio de transporte bajo la

${ }^{18}$ Diccionario Enciclopédico Popular Ilustrado. Salvat, años 1906-1914. 
modernización del mismo o si, definitivamente, se quedará como un patrimonio inerte y quieto en contra de su concepción del movimiento. Ante esto, se tendrían dos posturas: que vuelvan a ser estaciones de ferrocarril para un medio de transporte actualizado o que los edificios sean descontextualizados de su función y se reasigne una en pro de evitar su destrucción.

A su vez, se deben incentivar los métodos de enseñanza del diseño de estaciones de ferrocarril y de terminales terrestres y aéreas en las cuales se utilicen y apliquen los aciertos de lo ya creado, y se corrijan y mejoren las pautas y preceptos generadores de la arquitectura del transporte y la movilidad.

\section{Conclusiones}

El sistema ferroviario en Colombia y Latinoamérica tuvo una vida útil prospera, pero corta, ya que desde la inauguración del primer tendido hasta hoy no transcurrió mucho tiempo antes de que surgieran las causas del deceso como sistema comunes a la mayoría de países del cono sur, amparadas por políticas estatales, influencias por los fondos internacionales, los derivados del petróleo, así como los nuevos modos de transporte que dejaron sin sustento funcional aquel medio de transporte que produjo tan particulares aportes a la arquitectura.

Las construcciones ferroviarias por naturaleza fueron concebidas bajo la premisa de un funcionamiento en conjunto, como un sistema, por lo cual analizar un tipo de volumen como elemento singular resulta discordante. Los edificios vistos en conjunto permiten establecer relaciones formales, funcionales y técnicas, en las cuales se vislumbra y distingue la existencia de un patrón tipológico reflejado en las estaciones.

El futuro del patrimonio ferroviario en conjunto, tanto de edificios, rieles e instalaciones dependerá en gran parte de aquellas acciones que se realicen desde la gestión, la reutilización y los proyectos que genere la academia, siendo un pilar fundamental para su preservación incluyendo propuestas que tengan utilidad mediante el aprovechamiento funcional por parte de la sociedad actual que vislumbra en ellas el potencial de sostenibilidad que tanto reclama el patrimonio industrial y específicamente el ferroviario para subsistir.

Si solo se restauran los edificios de la arquitectura del movimiento se tendrá un simple método convencional, toda vez que recupera el inmueble o monumento a su estado de construcción sin importar que el tiempo ha pasado, que la ciudad, núcleo urbano, población, sistema de transporte, velocidades y comunicaciones han cambiado, carente de una nueva función, lo cual en la mayoría de casos ocasiona la destrucción del monumento y su completo aislamiento del perímetro que lo rodea tanto físico como social.

\section{Referencias}

Arango, S. (1989). Historia de la arquitectura en Colombia. Bogotá: Universidad Nacional de Colombia.

Arias, G. (2006). La segunda mula de hierro. Bogotá: Panamericana editores.

Bértola, L., y Gerchunoff, P. (2011). Institucionalidad y desarrollo económico en América Latina. Santiago de Chile: Naciones Unidas/Cepal.

Cárdenas, R. (2003). Como destruyen a Colombia: arrasamiento y muerte de los ferrocarriles nacionales. Girardot, Colombia: Editorial Chía.

Cloquet, L. (1900). Traite d'Architecture. Paris: Beranger.

Grego, C. (1989). Transformación y conservación del patrimonio. Bogotá: Escala editores. 
Currie, L. (1988). Bases de un programa de fomento para Colombia (2a Ed.). Bogotá: FONADE.

Daly, C. (1846). Revue générale de l'architecture et des travaux publics. París, Francia: Ducher et cie.

Ferrocarril de la Sabana. (1887). Empresa del ferrocarril de Cundinamarca. Arquitectura. Fc Sabana. Bogotá: Imprenta Echeverría Hnos.

Ferrari, M. (2011). El sistema ferroviario en el noroeste argentino. Arquitectura e instalaciones complementarias. Apuntes, 42 (1), 44-61.

Ferrari, M. (2011a). Los asentamientos urbanos producidos por la instalación del ferrocarril en el noroeste argentino. Apuntes 24 (1), 26-43.

Foucault, M. (1975). Vigilar y castigar. Buenos Aires: Siglo Veinte Editores.

Le Chatelier, L. (1845). Chemins de fer d'Allemagne. París: Librairie Scientifique-Industrielle de L. Mathias.

Loos, A. (1908). Ornamento y delito. Barcelona: G. Gili Editores.

Martínez, O. (2005). Manual para inventario de Bienes Culturales Inmuebles. Bogotá: Ministerio de Cultura / Dirección de Patrimonio.

Mayor, A. (2010). Centenario de un pionero del desarrollo El ingeniero Francisco Javier Cisneros 1836-1898. Credencial Historia, 102. Recuperado de http://www.banrepcultural.org/bibliotecavirtual/credencial-historia/numero-102/centenario-de-un-pionero-del-desarrollo-el-ingeniero

Montañez, G., Rodríguez, E., Torres, R., y Flórez, A. (1997). Geografía y ambiente: enfoques y perspectivas. Bogotá: Universidad de la Sabana.

Ordoñez, O. (1995). Arquitectura ferroviaria, documentos gráficos y escritos. Bogotá: Colcultura.

Osorio, J., y Acevedo, A. (2008). Paisaje cultural cafetero Risaralda Colombia. Pereira, Colombia: Universidad Católica Popular del Risaralda - Universidad Tecnológica de Pereira - Corporación Autónoma Regional del Risaralda

Reynaud, M. L. (1867). Traite d'Architecture. Paris: Dunod.

Rojas, P. (2016). Reutilización del Patrimonio: En torno a una teoría de conservación de las líneas ferroviarias Norte y Nordeste en Colombia (proyecto de investigación para tesis doctoral). Universidad de Mendoza, Argentina, Facultad de Arquitectura.

TICCIH (2003). Carta de Nizhny Tagil sobre el patrimonio industrial. Moscú, Rusia: Comité internacional para la conservación del patrimonio industrial.

Tartarini, J. (1995). Arquitectura ferroviaria en América Latina: algunas aproximaciones. Revista Escala, 21.

Tartarini, J. (2001). Arquitectura ferroviaria. Buenos Aires: Ediciones Colihue.

UNESCO. (2006). Xochimilco, Tlahuac, Milpa. Plan integral y estructura de gestión del polígono de Xochimilco. Mexico D.F.: Perichi editores. 